Methods Definite SLE and rheumatoid arthritis (RA) were diagnosed on the basis of criteria by the ACR. Study included 44 SLE patients (39 F,5 M; age 36.4 years), 71 RA patients (59 F, $12 \mathrm{M}$; age 49 years). The prevalence of warts was also determined in healthy madical students and their neighbours.

Results Warts occured significantly $(\mathrm{p}<0.012$, $\mathrm{p}<0.001)$ more often in patients with SLE than in the RA patients and healthy control patients respectively. Table shows the prevalence of warts in patients with SLE and control patients.

\begin{tabular}{llll}
\multicolumn{2}{l}{ Abstract AB0076 Table $\mathbf{1}$} & & \\
\hline & Warts (+) & Warts (-) & Total \\
\hline SLE & 16 & 28 & 44 \\
RA & 11 & 60 & 71 \\
Healthy Control & 14 & 91 & 105 \\
\hline
\end{tabular}

Conclusion The findings suggest that some deficiency in the immune mechanisms of patients with SLE predisposes them to develop warts.

\section{AB0077 CIPROFLOXACIN-RELATED ACUTE PERIPHERAL NEUROPATHY IN A PATIENT WITH SLE}

J Singh, R Brasington. Department of Medicine, Division of Rheumatology, Washington University School of Medicine, St. Louis, USA

10.1136/annrheumdis-2001.122

Background Ciprofloxacin is a broad-spectrum antibiotic commonly used for skin, respiratory tract and urinary tract infections. It is associated with a very few serious adverse effects. ${ }^{1,2}$ In a report of worldwide experience with ciprofloxacin, peripheral neuropathy was reported in one patient only, with no details available. ${ }^{3}$ We describe the first case of ciprofloxacin-related peripheral neuropathy in a patient with SLE.

Objectives

Methods

Results The patient, 18-yr-old African-American female, presented with five-day history of an acute onset of progressive tingling, numbness and weakness of both lower extremities. The symptoms began one day after the initiation of ciprofloxacin for treatment of urinary tract infection. At the time of hospital admission, patient was found to have bilateral symmetrical decrease in pain, temperature and light touch perception below knees, with weakness of both plantar- and dorsi-flexion of the ankle and an absence of bilateral ankle reflexes. Nerve conduction studies and EMG were done, which revealed a predominant sensory axonal neuropathy in lower extremities, with relative sparing of the motor component. MRI of the spine didn't reveal any evidence of transverse myelitis. A diagnosis of ciprofloxacinrelated peripheral neuropathy was made. Ciprofloxacin was discontinued. During the two day stay in the hospital, she started regaining the sensation in both lower extremities, without any other intervention. Within 10 days of the discontinuation of ciprofloxacin, her symptoms had completely resolved. She had no recurrence of the symptoms and no residual neurological deficit.

Conclusion Peripheral neuropathy is an uncommon manifestation of SLE. It is more rarely seen as adverse effect of ciprofloxacin. It is possible that the presence of SLE, and the concomitant use of hydroxychloroquine in our patient may have predisposed her to the occurrence of this rare adverse effect of ciprofloxacin. A similar case of possible drug interaction has been reported in a patient receiving therapy with ciprofloxacin, NSAID?s and chloroquine, who experienced neurological adverse effect. ${ }^{4}$

\section{REFERENCES}

1 Rahm V, Schacht P. Safety of ciprofloxacin. A review. Scand I Infect Dis Suppl. 1989:60:120-8

2 Schacht P, Arceri G, Hullmann R. Safety of oral ciprofloxacin. An update based on clinical trial results. Am J Med. 1989:87(5A):98S-102S

3 Reiter C, Pfeiffer M, Hullman RN. Safety of ciprofloxacin based on Phase IV studies in the Federal Republic of Germany. Am J Med. 1989;87(5A):103S-108S

4 Rollof J, Vinge E. Neurologic adverse effects during concomitant therapy with ciprofloxacin, NSAID?s and chloroquine: possible drug interaction. Ann Pharmacother. 1993;27(9):1058-9

\section{AB0078 PULSE METHYLPREDNISOLONE AND CYCLOPHOSPHAMIDE THERAPY IN THREE SYSTEMIC LUPUS ERYTHEMATOSUS PATIENTS WITH BRONCHIOLITIS OBLITERANS ORGANISING PNEUMONIA AS THE INITIAL MANIFESTATION}

JC Tseng, HH Cheng, RJ Hu, LY Lu. Allergy, Immunology and Rheumatology, Veterans General Hospital, Kaohsiung, Taiwan, R.O.C

\subsection{6/annrheumdis-2001.123}

Background Diverse pleuropulmonary manifestations are common in patients with systemic lupus erythematosus (SLE). Bronchiolitis obliterans organising pneumonia (BOOP) is a pathologic entity characterised by the formation of fibrous plugs within terminal bronchioles and alveolar ducts. Although BOOP has been associated with several connective tissue disorders, there are rare reports of BOOP in patients with SLE as the initial manifestation.

Objectives We describe three SLE patients with open lung biopsy-proved BOOP as the initial manifestation.

Methods All three cases presented with acute/subacute chest symptoms of fever, cough and dyspnea. Chest radiographs and CT scan of lung revealed bilateral pulmonary infiltrates. BOOP was confirmed by open lung biopsy. Pulmonary vasculitis was also demonstrated in lung histopathology in one case. The pulmonary lesions and respiratory illnesses responded to pulse intravenous methylprednisolone and cyclophosphamide therapy. Results

Abstract AB0078 Table 1

\begin{tabular}{|c|c|c|c|c|c|c|c|}
\hline & Sex & Age & ANA & anti-ENA & anti-dsDNA & Anticardiolipin antibody & Duration of pulse cyclophosphamide therapy \\
\hline Case 1 & Female & 43 & 1:160, speckled & SS-A, SS-B & Negative & Positive & 3 months \\
\hline Case 2 & Male & 56 & 1:320, homogeneous & Negative & $69 \mathrm{IU} / \mathrm{ml}$ & Positive & 3 months \\
\hline Case 3 & Male & 47 & 1:320, homogeneous & Negative & $>400 \mathrm{IU} / \mathrm{ml}$ & Negative & 2 months \\
\hline
\end{tabular}

Clinical and laboratory data. 


\section{Conclusion}

\section{REFERENCES}

1 Otsuka F, Amano T, Hashimoto N, Takahashi M, Hayakawa N, Makino H, Ota Z, Ogura T. Bronchiolitis obliterans organizing peumonia associated with systemic lupus erythematosus with antiphospholipid antibody. Intern Med. 1996;35 (4):341-4

2 Imasaki T, Yoshii A, Tanaka S, Ogura T, Ishikawa A, Takahashi T. Polymyositis and Sjogren's syndrome associated with bronchiolitis obliterans organizing pneumonia. Intern Med. 1996;35(3):231-5

3 Min JK, Hong YS, Park SH, Park JH, Lee SH, Lee YS, Kim HH, Cho CS, Kim HY. Bronchiolitis obliterans organizing pneumonia as an initial manifestation with systemic lupus erythematosus. J Rheumatol. 1997:24(11):2254-7

4 Shinohara T, Hidaka T, Matsuki Y, Ishizuka T, Takamizawa M, Kawakami M, Kikuma $H$. Rapidly progressive interstitial lung disease associated with dermatomyositis responding to intravenous cyclophosphamide pulse therapy. Intern Med. 1997;36(7):519-23

\section{AB0079 CYCLOPHOSPHAMIDE EXPOSURE DURING PREGNANCY: TWO CASES}

Ý Ertenli, V Cobankara, S Apras, S Kiraz, MA Oztürk, M Çalgüneri. Rheumatology, Hacettepe University School of Medicine, Ankara, Turkey

\subsection{6/annrheumdis-2001.124}

Background Lupus nephritis is a severe clinical entity that should be treated with cytotoxic drugs. Cyclophospamide is an effective cytotoxic agent against lupus nephritis. Cyclophosphamide is probably a potent teratogen. Severe birth defects reported in several cases after cyclophosphamide given as little as $200 \mathrm{mg}$ during pregnancy. Some authorities, however, recommend the use of cyclophosphamide in life-threatening lupus during pregnancy. Objectives In this report, we present two cases that used cyclophosphamide during unpredicted pregnancy.

Methods

Results Case-I: A 20-year-old female was diagnosed as SLE with arthritis, photosensitivity, haemolytic anaemia, leukopenia, proteinuria and positive antinuclear and anti-ds-DNA antibodies. Anti-phospholipid antibodies were negative. The disease remained under control with corticosteroids, hydroxychloroquine and cyclophosphamide. In June 1999, it was noticed that she had been pregnant for 24 weeks and she had received five cycles of intravenous pulse cyclophosphamide $(500 \mathrm{mg}$ for each cycle, $2500 \mathrm{mg}$ total dose). Until the end of pregnancy, the treatment was continued with corticosteroids. The baby is now 16 months-old and in good health.

Case-II: A 21-year-old female patient presented with arthritis, carditis, and proteinuria. She had positive antinuclear, anti-dsDNA, and negative anti-phospholipid antibodies, and the diagnosis of SLE was made. She was treated with oral corticosteroids and intravenous cyclophosphamide. In September 1999, while she was in remission, it was noticed that she had been pregnant for 12 weeks. Since that time, she had been given intravenous $500 \mathrm{mg}$ pulse cyclophosphamide twice (1000 mg totally). During pregnancy, only corticosteroids and salicylic acid were given. In March 2000, she delivered a healthy male baby. The baby is now 9 month old and healthy.

Conclusion Although fertility is decreased in SLE due to lupus nephritis and cyclophosphamide treatment, some pregnancies may occur. The pregnancies of SLE patients with anti-phospholipid syndrome have poorer prognosis. The absence of anticardiolipin antibodies in these two patients might have protected from poor outcome. Some authors believe that cyclophosphamide should not be used due to its teratogenic effect. Reported abnormalities due to cyclophosphamide during pregnancy include absent thumbs, absence of the great toes or all toes, palatal abnormalities, and a single coronary artery. However there are also reports of normal infants born from cyclophosphamidetreated mothers, and cyclophosphamide was proposed in lifethreatening lupus. Experiences of cases like the present two may help the physician to make decisions on cyclophosphamide therapy during pregnancy in life-threating cases.

\section{AB0080 TREATMENT FAILURE PULMONARY HAEMORRHAGE OF SISTEMIC LUPUS}

S Holgado, A Olivé, M Gumà, V Ortiz-Santamaría, M Valls, A Lafont, E Casado, X Tena. Rheumatology, Hospital Universitari Germans Trias, Badalona, Spain

10.1136/annrheumdis-2001.125

\section{Background}

Objectives To describe the treatment and outcome of patients with SLE and pulmonary haemorrhage.

Methods Retrospective study (1989-2000). Centre: Universitary Hospital. Area: 700,000 inhabitans. SLE clinic: 154 SLE patients were reviewed. All patients fulfilled the ACR criteria for SLE.

Results All patients received plasmapheresis, 3 bolus of cyclophosphamide $12 \mathrm{mg} / \mathrm{kg} /$ day and prednisone $2 \mathrm{mg} / \mathrm{kg} /$ day iv. Mechanical ventilation was employed in all patients. Death was secondary to nosocomial infections.

\begin{tabular}{|c|c|c|c|c|c|}
\hline Age & Sex & Evolution of SLE (month) & SLEDAI & anti-DNA & $\begin{array}{l}\text { Complement } \\
\text { C3/C4 }\end{array}$ \\
\hline 43 & Female & 6 & 9 & $1 / 640$ & $10 / 2,1$ \\
\hline 63 & Female & 120 & 21 & $1 / 2500$ & $46 / 14$ \\
\hline 74 & Female & 40 & 4 & Negative & $32 / 12$ \\
\hline
\end{tabular}

Conclusion Pulmonary haemorrhage is a rare and often fatal complication of SLE. There are no uniform recommendations for treatment. Mechanical ventilation and inmunosupresors were a risk factor for a increase mortality.

\section{AB0081 CENTRAL NERVOUS SYSTEM INVOLVEMENT IN CONNECTIVE TISSUE DISEASES - OUR EXPIRIENCE}

DZ Stefanovic, BC Glisic, MM Cirkovic, ZV Andjlekovic, MR Petronijevic, DV Mitrovic, MM Popovic. Clinics of Rheumatology, Military Medical Academy, Belgrade, Yugoslavia

\subsection{6/annrheumdis-2001.126}

Background Central nervous system involvements are the most severe clinical manifestations in connective tissue diseases.

Objectives We estimated prevalence of central nervous system (CNS) involvement in our patients.

Methods They were followed up during ten years period.

Results Among 250 patients with systemic lupus erythematosus (SLE), 17 (7\%) had alterations of CNS: cerebrovascular insult (5 pts), seizures (4 pts), psychosis (3 pts), transversal myelitis (2 pts), cranial nerve paralysis (2 pts) and psychoorganic syndrome (1 pt). In 3 pts SLE expressed primarily with CNS manifestations. Thirteen patients of $64(20 \%)$ with Behcet disease had impairment of CNS: aseptic meningoencephalitis (2 pts), pyramid syndrome (2 pts), cerebelar-ataxic syndrome (2 pts), myelopathy (2 pts), cranial nerve paralysis (2 pts), psychosis (1 pt), 